\title{
Rethinking Aggression: A Typological Examination of the Functions of Aggression
}

\section{Citation}

Little, Todd D., Jessica Brauner, Stephanie M. Jones, Matthew K. Nock, and Patricia H. Hawley. 2003. "Rethinking Aggression: A Typological Examination of the Functions of Aggression." Merrill-Palmer Quarterly 49 (3): 343-369. doi:10.1353/mpq.2003.0014.

\section{Published Version}

doi:10.1353/mpq.2003.0014

\section{Permanent link}

http://nrs.harvard.edu/urn-3:HUL.InstRepos:34721612

\section{Terms of Use}

This article was downloaded from Harvard University's DASH repository, and is made available under the terms and conditions applicable to Other Posted Material, as set forth at http:// nrs.harvard.edu/urn-3:HUL.InstRepos:dash.current.terms-of-use\#LAA

\section{Share Your Story}

The Harvard community has made this article openly available.

Please share how this access benefits you. Submit a story.

Accessibility 


\title{
Rethinking Aggression: A Typological Examination of the Functions of Aggression
}

\author{
Todd D. Little \\ University of Kansas \\ Jessica Brauner, Stephanie M. Jones, and Matthew K. Nock \\ Yale University \\ Patricia H. Hawley \\ University of Kansas
}

\begin{abstract}
We compared five subgroups of aggressive youth $(n=1,723$, Grades 5 through $10)$ on a number of adjustment correlates. The subgroups were determined by the self-reported functions (i.e., "why") of their aggressive behavior: (a) an "instrumental" group who were high on instrumental reasons only; (b) a "reactive" group who were high on reactive reasons only; $(c)$ a "both" group who were high on both dimensions; (d) a "typical" group who were moderate on both dimensions; and (e) a "neither" group who were low on both dimensions. The reactive and both groups showed consistent maladaptive patterns across the adjustment correlates. The instrumental and typical groups both showed generally adaptive and well-adjusted patterns. Surprisingly, the neither group revealed high levels of aggressive acts and showed consistent maladaptive patterns on the correlates. These distinct profiles highlight the utility of a typological approach to classifying aggressive youth and have implications for both assessment and intervention.
\end{abstract}

Antisocial and aggressive behaviors are a leading cause of referral to inpatient and outpatient clinics during adolescence, accounting for

Todd D. Little and Patricia H. Hawley, Department of Psychology, University of Kansas; Jessica Brauner, Stephanie M. Jones, and Matthew K. Nock, Department of Psychology, Yale University.

The Max Planck Society and Yale University provided partial support for this work. We would like to express our gratitude for the feedback and comments of our colleagues in the Agency in Development Lab (Todd D. Little, director) of the Department of Psychology at Yale University and to the members of the New England Social Development Consortium (NESDC). Parts of this work were presented at the biennial meeting of the Society for Research in Child Development in Minneapolis, April 2001.

Authorial contributions were equivalent. Correspondence should be addressed to the first author at the Department of Psychology, 1455 Jayhawk Blvd., University of Kansas, Lawrence, KS 66045. E-mail: yhat@ku.edu.

Merrill-Palmer Quarterly, July 2003, Vol. 49, No. 3, pp. 343-369. Copyright (C) 2003 by Wayne State University Press, Detroit, MI 48201. 
one-third to one-half of all such referrals (Kazdin, 1995). These high referral rates are alarming given the negative outcomes associated with aggression and the fact that aggressive behavior can often continue into late adolescence and adulthood (Olweus, 1979; Pulkkinen, 1996). On the other hand, some aggressive behavior is quite normative during adolescence and may even have adaptive benefits (Hawley, 1999; Tremblay, 2000). In our view, the plethora of negative consequences associated with aggressive behavior, coupled with the seemingly paradoxical advantages of aggression, highlight the need for improved approaches to identify and classify subtypes of aggressive youth.

As Tremblay (2000) has recently noted, efforts to identify subtypes of aggressive individuals have had only limited success. In this study, we address this challenge by adopting a person-centered typological approach (Magnusson, 1998) to classify subgroups of aggressive youth. A typological approach has the potential not only to identify specific subgroups of youth for whom aggression is clearly maladaptive but also to reveal subgroups of aggressive youth for whom modest amounts of aggressive behavior are generally normative and possibly beneficial. In this study, we examine five distinct subgroups of aggressive youth (see later) based on the functions (i.e., the whys, or purposes) of their aggressive behavior. Because a functional perspective directly addresses why aggressive behavior is occurring, it has great potential to broaden our understanding and treatment of aggressive behavior.

\section{Dimensions of Aggressive Behavior}

Recent studies generally support the distinctiveness and differential predictive characteristics of various dimensions of aggression (Atkins \& Stoff, 1993; Crick, Casas, \& Mosher, 1997; Poulin \& Boivin, 1999, 2000; Price \& Dodge, 1989; Pulkkinen, 1996). For example, assessing relational aggression (instead of relying only on overt-physical measures of aggression) has narrowed the gap in the reported rates of aggression for males and females (Crick \& Grotpeter, 1995; Delveaux \& Daniels, 2000). Similarly, Poulin and Boivin $(1999,2000)$ differentiated between proactive and reactive facets of aggression and found that boys' proactive aggression predicted increased conflict in stable friendships over the course of a school year, while reactive aggression predicted a decrease in conflict.

Although such studies have identified distinct dimensions of aggression, nearly all of them have confounded the behaviors' form and function and, not surprisingly, have consistently found quite high correlations between the different facets of aggressive behavior (Crick \& Grotpeter, 1995; Dodge \& Coie, 1987; Little, Jones, Henrich, \& 
Hawley, 2003; Poulin \& Boivin, 2000; Price \& Dodge, 1989). For example, both instrumental and reactive aggression are often measured with items that also tap overt behaviors as the form of aggression and typically correlate in the .6 to .7 range (Poulin \& Boivin, 2000; Price \& Dodge, 1989). Because of this confound, proper identification, assessment, and treatment of aggressive youth is undermined. In our view, the ability to purely identify the functions of aggression (i.e., knowing the reasons why an adolescent is aggressive separately from how he or she is aggressive) is critical because different intentions would necessitate different approaches to intervention and treatment.

To address this common confound, Little et al. (2003) developed a measurement and analysis system that disentangles various forms (overt vs. relational) and functions (instrumental vs. reactive) of aggression. In their framework, overt aggression encompasses physical and verbal behaviors directed at another individual while relational aggression includes purposeful manipulation of and damage to another's social relationships. Instrumental aggression incorporates behaviors that portend self-serving outcomes (i.e., more offensive in function), while reactive aggression is more defensive in nature, emerging in response to perceived provocations or similar antecedent situations.

Using a confirmatory structural equations modeling approach, Little et al. (2003) found strong support for both the internal (i.e., the convergent and discriminant features of the measured aggression constructs) and the external (i.e., the predictive relations with various outcomes) validity of their instrument. Consistent with the literature, they found that the overt and relational forms of aggression are highly overlapping but uniquely predictive aspects of aggressive behavior. However, in stark contrast to past research, Little et al. also found that, after controlling for the over-riding forms of aggressive behavior, instrumental and reactive aggression were, in fact, orthogonal facets of aggressive acts. This novel outcome emerged because their distinctive measurement and analysis system eliminates the inherent confound between the forms (e.g., overt vs. relational) of aggression and its functions (i.e., the whys, or purposes). Disentangling the "what" from the "why" of aggressive behavior has the advantages of examining (a) how each dimension relates to others and (b) how they relate uniquely to different outcome measures.

\section{Reporter Differences}

Although the Little et al. (2003) measurement and analysis system addresses one source of inconsistency, other problems with assessing aggression arise because of discrepancies between the different reporters 
of aggressive behavior (Ledingham, Younger, Schwartzman, \& Bergeron, 1982). For example, Pakaslahti and Keltikangas-Jaervinen (2000) examined peer, teacher, and self-ratings of overt and relational aggression and found that the correlation was highest between the peer and teacher reports, followed by teacher and self-reports, with the lowest correlation between peer and self-reports. They also found higher consistency among reporters for overt forms of aggression than for relational forms. However, the majority of these crossrater correlations were in the .10 to .65 range, suggesting that reporters disagree more than they agree when it comes to identifying aggressive behavior.

A likely explanation for these discrepancies is that different raters view a target individual's aggressive behaviors in different contexts and situations (Achenbach, McConaughy, \& Howell, 1987). Given each reporter's unique perspective and potential biases, a more thoughtful rationale is warranted when choosing which rater to use. In our view, taking into account the functions and forms of aggressive behavior that are of interest can provide such a basis. To examine the instrumental or reactive functions of aggression, self-ratings would be preferred because of the inherent difficulty in judging intent and because, beginning in late childhood, one's sense of self is sufficiently developed such that the individual would have some insight as to why he or she is acting aggressively. On the other hand, to assess the forms of aggression, multiple sources would be preferred because of the context specificity of the expressed forms of aggression. Instead of relying on any one reporter or an aggregate of all reporters, taking a unique look at several reporters (self, friend, peer, parent, and teacher) to identify cross-situation similarities and differences in the expression of aggressive behavior is warranted.

\section{Typologies of Aggression Based on Self-Reported Function}

For this study, we were particularly interested in the relations between the instrumental and reactive functions of aggression for identifying and classifying subgroups of aggressive youth. Our specific interest in focusing on the functions of aggressive behavior stems from the fact that although attention to the distinction between different forms of aggressive behavior (e.g., overt vs. relational) is instructive, it provides little information about why individuals engage in aggressive behavior. In our view, a better understanding of the functions, or purposes, of aggressive behaviors is necessary to develop more compre- 
hensive conceptualizations and more powerful approaches to assessing and treating aggressive behaviors.

As mentioned, a notable outcome of the Little et al. (2003) study was that, when the confound of the form of the aggression is controlled for, the instrumental and reactive reasons for aggressive behavior emerge as uncorrelated dimensions. This finding was a primary impetus for the current study. Using the same sample of adolescents as the Little et al. study, we significantly extend their earlier validation study by applying a typological analysis to the instrumental and reactive reasons for aggressive actions.

The independence of the two functional dimensions is particularly well suited to a typological examination because individuals can be logically divided into meaningful subgroups based on where they lie along the two dimensions. A typological classification based on the relative standing along these independent dimensions offers a unique perspective on the resulting subgroups that is not captured by typical continuous-variable approaches (e.g., interaction terms; Hawley, Little, \& Pasupathi, 2003). In the absence of absolute cutoffs, the categories are created by dividing the distribution of self-report scores on reactive reasons into thirds (i.e., at the $33^{\text {rd }}$ and $66^{\text {th }}$ percentiles) and crossing them with a similar tripartite breakdown on instrumental reasons (see Hawley et al., 2003; Hawley, this issue). This procedure yields a balanced 3 by 3 matrix of possible groups (i.e., because the two distributions do not overlap systematically, a given score on one dimension is equally likely to be coupled with a high, medium, or low score on the other dimension). On the basis of their logical similarities, some of the cells (e.g., the three middle cells) can be further collapsed to yield at least five distinct typological profiles of aggressive youth (see Figure 1). Note that because these subgroups are defined based on the form-free reasons for their aggressive behavior (i.e., the form of the aggression is controlled), the absolute amounts of the aggressive behavior can vary freely. For example, a child who aggresses primarily for instrumental reasons might behave aggressively quite rarely or quite often.

\section{Specific Hypotheses}

Our first goal was to examine the amount or frequency of overt and relational aggression exhibited by the different subgroups. As mentioned, the subgroups are defined based on the reasons for their aggressive behavior, which are independent of the amount of the aggressive behavior. We were particularly interested in the patterns of aggression exhibited by each subgroup as rated by each reporter (i.e., self, friend, 


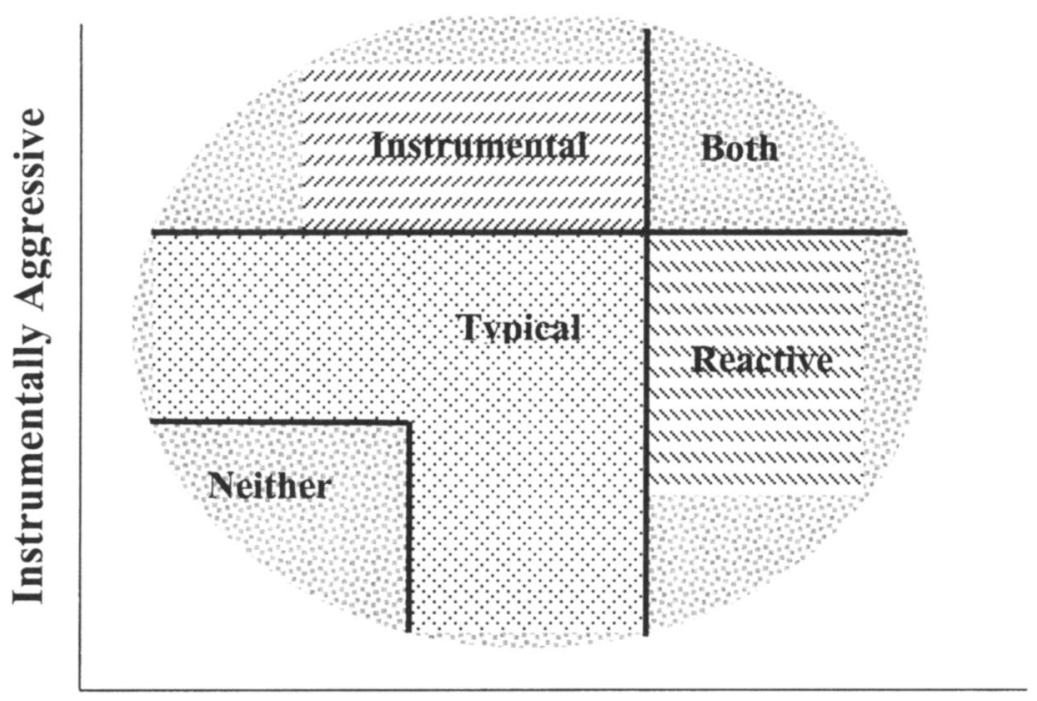

\section{Reactively Aggressive}

Figure 1. Classification of subgroups of aggressive youth based on their standings on instrumental and reactive aggression.

peer, parent, and teacher). As a side note, we expected the correlations among raters to be generally low, with the highest cross-rater correlations emerging between peer and teacher reports, because both are observers of the school context. We also expected to find higher consistency among reporters for overt aggression than for relational, because overt aggression is more visible than relational aggression.

Our second goal was to examine subgroup differences on a number of adjustment variables in an effort to identify potential deficits, as well as benefits, of aggressive behavior depending on the defining typological characteristics of each subgroup. To accomplish this goal, we chose a representative set of constructs that could adequately characterize each subtype, covering (a) personality, (b) social motivation and competence, and (c) academic adjustment. Because of the cross-sectional nature of this study, we refer to these variables as correlates of aggression. For the first set of adjustment correlates, we chose three personality characteristics that have been associated with aggressive behavior: hostility, frustration intolerance, and shyness (Asendorpf, 1989; Coie \& Dodge, 1998; Keltner, Young, \& Buswell, 1997; Seitz \& Rausche, 1992). We obtained self-report, peer-nomination, and best-friend assessments 
on these three characteristics. As an adjunct to these dimensions, we selected two academic indices (problem-solving ability and actual school performance) to evaluate the academic status of these subgroups. Finally, we assessed three self-reported indices of social motivation and competence (intrinsic vs. extrinsic social orientation and social self-concept) in an effort to identify potential antecedents and consequents of the different subgroups of aggressive youth.

In terms of hypotheses, we generally expected that the different subgroups would exhibit differences in the amounts of aggressive behavior (i.e., on the overt and relational forms of aggression) as well as unique profiles on the selected correlates. In terms of specific subgroup hypotheses, we expected the typical group to exhibit generally normative patterns of aggressive behavior (i.e., low to average levels of relational and overt aggression) and exhibit a generally positive profile on the correlates (i.e., low to average levels on shyness, hostility, and frustration intolerance; and average to high levels on social motivation, social competence, and school performance), because this group lies in the middle ground on both instrumental and reactive reasons for their aggressive behavior (see Figure 1). Because the instrumental use of aggression is planful and reward or outcome oriented (Coie \& Dodge, 1998), we expected the instrumental group to exhibit average levels of overt and relational aggression but to not show signs of maladaptation on the adjustment correlates (i.e., low levels on shyness, hostility, and frustration intolerance; and average to high levels of social competence and school performance). That is, we expected the instrumental group to be very much like the typical group. Because the reactive use of aggression is associated with a number of self-regulatory and attributional deficits (Coie \& Dodge, 1998), we expected the reactive group to reveal average to high levels of relational and overt aggression; average to low levels on school performance, social motivation, and social competence; and high levels on hostility, shyness, and frustration intolerance. Because the both group employs aggression purposefully and in response to provocation, we expected them to exhibit high levels of overt and relational aggression; low levels of social competence and school performance; and high levels of shyness, hostility, and frustration intolerance. That is, we expected the both group to be similar to the reactive group and perhaps exhibit even more negative patterns because of the expected elevated frequency of aggressive acts. Lastly, given their low standing on both instrumental and reactive reasons for their aggressive behavior, we expected the neither group to be generally reserved and meek (i.e., shy, evince low levels of overt and relational aggression, and average to low levels of social competence, frustration intolerance, and hostility). 


\section{Method}

\section{Participants}

Participants consisted of $5^{\text {th }}$ to $10^{\text {th }}$ graders (mean age, 14.0 years) who were selected from each of the basic school types (elementary, college-bound, vocational, and comprehensive), serving lower to upper middle class suburbs of Berlin, Germany. In total, 1,723 students from five schools participated, reflecting over $75 \%$ school-wide participation. Written informed consent was obtained from both parents and youths. The ethnic makeup of the sample was roughly $82 \%$ German, $12 \%$ Turkish, and $6 \%$ other. For this study, gender, grade, and ethnicity effects, which were generally minimal, were included in all analyses, but, because our focus was on the subgroups of aggressive youth and we did not have specific predictions regarding interactions among them, we report only pronounced $(p<.005)$ interactive effects.

\section{Measures}

As part of a larger study, participating students completed questionnaires in groups of approximately 30 per class during three 45minute sessions spanning approximately 2 weeks. For the $5^{\text {th }}$ and $6^{\text {th }}$ grade participants, a proctor read the questions aloud while a second proctor assisted. Participants in the upper grades completed the questionnaires independently while a proctor circulated to answer any questions. Order of questionnaire administration was counterbalanced. Except for the aggression instrument, which was codeveloped in English and German, the various measures were either translated into German (using back-translation and bilingual committee evaluation procedures) or adapted from established measures in the literature.

To obtain peer nominations of the constructs, we used standard sociometric procedures (i.e., students were asked to nominate up to three classmates for each item). For the friendship assessments, students listed up to three very best friends and rated each on a number of dimensions (see later). Only mutual (i.e., both friends reciprocally nominated each other) best friends' evaluations of the focal participant were utilized ( $n=$ $1,164)$. Approximately $70 \%$ of the teachers and parents also filled out a questionnaire about the participating children, rendering valid responses for 733 of the participants from teachers and 877 from parents.

\section{Aggression}

The self-reported aggression constructs were assessed with six 6item subscales designed to differentiate the underlying forms and the functional expressions of aggression-overt aggression ("I'm the kind of person who often fights with others," $\alpha=.79$ ), overt-reactive aggres- 
sion ("When I'm hurt by someone, I often fight back," $\alpha=.82$ ), and overt-instrumental aggression ("I often start fights to get what I want," $\alpha=.84$ ) as well as relational aggression ("I'm the kind of person who tells my friends to stop liking someone," $\alpha=.62$ ), relational-reactive aggression ("If others have threatened me, I often say mean things about them," $\alpha=.63$ ), and relational-instrumental aggression ("I often tell my friends to stop liking someone to get what I want," $\alpha=.78$ ). A 4-point scale (never, seldom, often, always) was used (see Little et al., 2003, for all items and detailed validity information).

Following the analytic procedures outlined by Little et al. (2003), the form information (i.e., overt or relational) was separated from the instrumental and reactive aggression constructs, leaving two variables that reflect the unconfounded functions of aggression. Specifically, each construct that contains functional information (e.g., overtreactive aggression) is regressed on to the construct that contains only the form information (e.g., overt aggression). The scores for the two instrumental residuals were averaged to index instrumental aggression $(\alpha=.82)$ and the scores for the two reactive residuals were averaged to index reactive aggression $(\alpha=.67)$. Participants were assigned to the five subgroups based on their standing on the two indexes.

A first subgroup, termed both, includes those participants above the $66^{\text {th }}$ percentile on both instrumental and reactive reasons (i.e., this group reports that their reasons for aggressing are both defensive, in reaction to provocation, and offensive, in planful pursuit of a desired objective). A reactive subgroup includes participants above the $66^{\text {th }}$ percentile for reactive reasons but below the $66^{\text {th }}$ percentile for instrumental reasons. Similarly, an instrumental subgroup includes those above the $66^{\text {th }}$ percentile for instrumental reasons but below the $66^{\text {th }}$ percentile for reactive reasons. A neither subgroup includes those participants below the $33^{\text {rd }}$ percentile for both instrumental and reactive reasons. Finally, the typical group includes those who score below the $66^{\text {th }}$ and above the $33^{\text {rd }}$ percentile range on both self-reported instrumental and reactive reasons. The frequencies for the subgroups are listed in Table 1.

For the other reports of overt and relational aggression (using the same "pure" overt and relational aggression items as the self-report battery), all raters showed acceptable levels of reliability. For overt aggression the reliabilities were: .88 for teachers, .81 for parents, .65 for best friends, and .89 for peer nominations. For relational aggression the reliabilities were: .76 for teachers, .67 for parents, .72 for best friends, and .87 for peer nominations. 
Table 1. Frequency Distributions of Participants Across the Five Subgroups of Aggressive Youth

\begin{tabular}{lcccccc}
\hline & & \multicolumn{2}{c}{ Gender \% } & & \multicolumn{2}{c}{ Ethnicity \% } \\
\cline { 3 - 4 } \cline { 5 - 6 } Subgroup & $N$ & Males & Females & & Majority & Minority \\
\hline Both & 217 & 60 & 40 & & 76 & 24 \\
Instrumental & 368 & 53 & 47 & & 86 & 14 \\
Reactive & 368 & 44 & 56 & & 74 & 26 \\
Typical & 552 & 42 & 58 & & 88 & 12 \\
Neither & 218 & 44 & 56 & & 82 & 18
\end{tabular}

Note. The distribution by gender was not uniform, $x_{(4, n=1723)}^{2}=28.2, p<.0001$, nor was the distribution by ethnicity, $x_{(4, n=1723)}^{2}=41.3, p<.0001$. No pronounced grade differences emerged, $\chi^{2}{ }_{(20, n=1723)}=33.5, p=.03$.

\section{AgGression Correlates}

For the social motivation variables, 18 items were selected from the Multi-CAM questionnaire (Little \& Wanner, 1997) to examine intrinsic social motives (e.g., "Why is it that you try to make new friends? Is it because you like to do it?"; Cronbach's $\alpha=.88$ ) and extrinsic social motives ("Is it because you want to be popular?"; $\alpha=.87$ ). The social competence measure was adapted from Harter's (1982) self-concept measure ("I find it easy to be with others," "I find it hard to make friends"-reversed; $\alpha=.75$ ). For the measures of shyness, we adapted Asendorpf's (1989) subscales to include self-report (e.g., "I feel timid and shy around others"; $\alpha=.91$ ), a single peer-nomination item ("Who is shy?"; $\alpha=\mathrm{n} / \mathrm{a}$ ), and friend report (e.g., "Is this friend shy?"; $\alpha=.76$ ). Both the hostility and frustration intolerance measures were adapted from subscales of Seitz and Rausche's (1992) personality inventory for children. Hostility also included self-report (e.g., "I often pick on others"; $\alpha=.71$ ), peer nomination (e.g., "Who is mean to others?"; $\alpha=.70$ ), and friend report (e.g., "Is this friend nice to others?"-reversed; $\alpha=.72$ ). Frustration intolerance also included selfreport (e.g., "I easily get angry when things don't go the way I want"; $\alpha$ $=.83$ ), a single peer-nomination item ("Who gets upset or angry easily?"; $\alpha=\mathrm{n} / \mathrm{a}$ ), and friend report (e.g., "Does this friend get angry easily with others?"; $\alpha=.70$ ). Regarding school-related correlates, we collected the teacher-assigned marks in verbal and math performance as a combined achievement variable $(\alpha=.79)$ and we used Raven's progressive matrices as an index of problem-solving ability (Raven, 1971; $\alpha=.91)$. 


\section{Results}

We present the results in two parts. First we examine the correlations among overt and relational aggression across the different raters. Second, we examine the subgroup mean-level differences on the overt and relational forms of aggression as well as the selected correlates.

We used a standard Confirmatory Factor Analysis (CFA) to examine the intercorrelations among the overt and relational forms of aggression as reported by the self, parents, teachers, peers, and best friends. To evaluate model fit we used three standard fit indexes: Then non-normed fit index (NNFI) and the incremental fit index (IFI), for which values greater than .90 are deemed adequate, and the root mean squared error of approximation (RMSEA), for which values of less than .08 are deemed acceptable. The CFA model fit the data extremely well with an NNFI of .95, IFI of .94, and an RMSEA of .041.

In terms of the obtained latent correlations among the reporters, peer and teacher reports, as expected, had the highest cross-rater correlations ranging from .32 to .52 (see Table 2). Parent- and self-report ratings were modestly correlated, ranging from .26 to .33 , while those between parent and friend report were extremely low, ranging from .00 to .11. Overall, higher consistency was found for overt aggression between the different reporters, ranging from .24 to .52 , with the exception of friend and self-report, friend and parent report, and peer and parent report. Bearing in mind that the correlations in Table 2 are disattenuated (i.e., the effects of unreliability are controlled), the high correlations between overt and relational aggression within each reporter are somewhat higher than reported in the literature but at a level one would expect given the typical levels of reliability in assessing aggression (Crick \& Grotpeter, 1995; Delveaux \& Daniels, 2000).

To examine the between-subgroup mean differences on the various measures, we conducted a series of three set-wise inclusive MANOVAs followed by univariate ANOVAs that included gender, grade, and ethnicity as well as their interactions. Specifically, for each outcome measure, we first included gender, grade, ethnicity, and all of their possible interactions. In the second step, we added the subgroup variable to evaluate the significance of its contribution above and beyond the demographic variables. This step reflects our focal examination of the subgroup differences. In the third and final step, we added all the possible interaction terms of the subgroup variable with the demographic variables to explore any possible interactions with the aggression subgroups. Because of the sample sizes and the lack of specific interaction 
Table 2. Latent Correlations Between Self, Friend, Peer, Teacher, and Parent Report

\begin{tabular}{|c|c|c|c|c|c|c|c|c|c|}
\hline \multicolumn{2}{|c|}{ Self-rated } & \multicolumn{2}{|c|}{ Friend-rated } & \multicolumn{2}{|c|}{ Peer-rated } & \multicolumn{2}{|c|}{ Teacher-rated } & \multicolumn{2}{|c|}{ Parent-rated } \\
\hline Overt & Relat. & Overt & Relat. & Overt & Relat. & Overt & Relat. & Overt & Relat. \\
\hline \multicolumn{10}{|l|}{1.0} \\
\hline .84 & 1.0 & & & & & & & & \\
\hline .19 & .17 & 1.0 & & & & & & & \\
\hline .18 & .24 & .95 & 1.0 & & & & & & \\
\hline .31 & .20 & .25 & .21 & 1.0 & & & & & \\
\hline .21 & .21 & .15 & .20 & .72 & 1.0 & & & & \\
\hline .24 & .19 & .24 & .17 & .52 & .39 & 1.0 & & & \\
\hline .15 & .13 & .16 & .09 & .33 & .32 & .86 & 1.0 & & \\
\hline .33 & .28 & .06 & .11 & .26 & .27 & .27 & .23 & 1.0 & \\
\hline .28 & .26 & .00 & .07 & .14 & .24 & .18 & .18 & .87 & 1.0 \\
\hline
\end{tabular}

Note. Tabled values are disattenuated correlations based on latent LISREL estimates, with sources of measurement error removed. Overt = overt-direct aggression; Relat. = relational-indirect aggression. The CFA model fit the data extremely well with an NNFI of .95, IFI of .94, and an RMSEA of .041 .

hypotheses, we report only those effects that were significant at the .005 level. The MANOVA groupings (20 in all) were based on source of report (self, peer, friend, teacher, parent) and class of variable (i.e., overt and relational aggression were grouped; hostility, frustration, and shyness were grouped; Raven and achievement were grouped; and motivation and self-concept were grouped). We also conducted four planned comparisons among the five subgroups. First, we compared the instrumental and typical groups against the reactive and both groups because we expected generally opposite patterns across these groups. For the second and third comparisons, we contrasted (a) the instrumental against the typical group and (b) the reactive group against the both group. For the last comparison, we contrasted the neither group with the typical group.

Figure 2 displays the mean-level differences in the amount of aggression among the five subgroups as rated by the different reporters. As seen in Table 3, each MANOVA and ANOVA was significant, with the exception of the teacher ratings. Although a supplemental MANOVA that included rater as a factor revealed that the subgroup by rater interaction was significant, $F(32,12264=2.63), p<$ .01 , visual inspection of Figure 1 indicates considerable similarity across the raters in the pattern of subgroup differences for both overt 
A) Overt Aggression

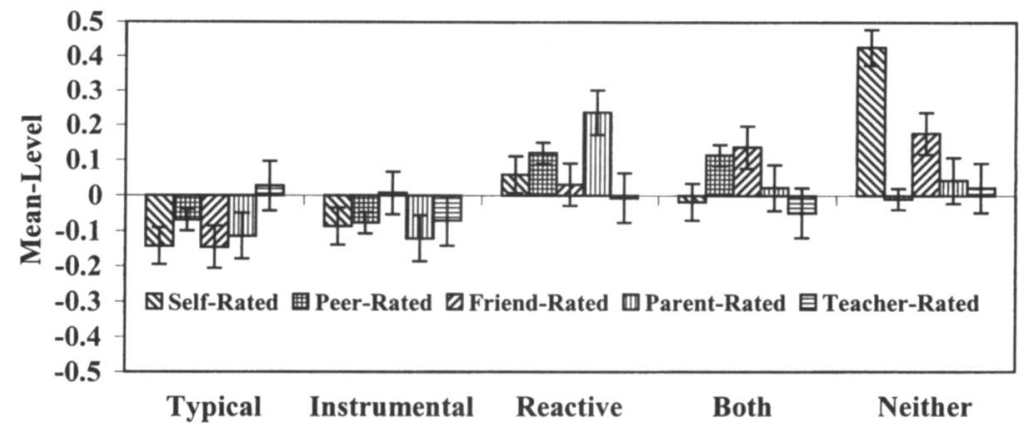

B) Relational Aggression

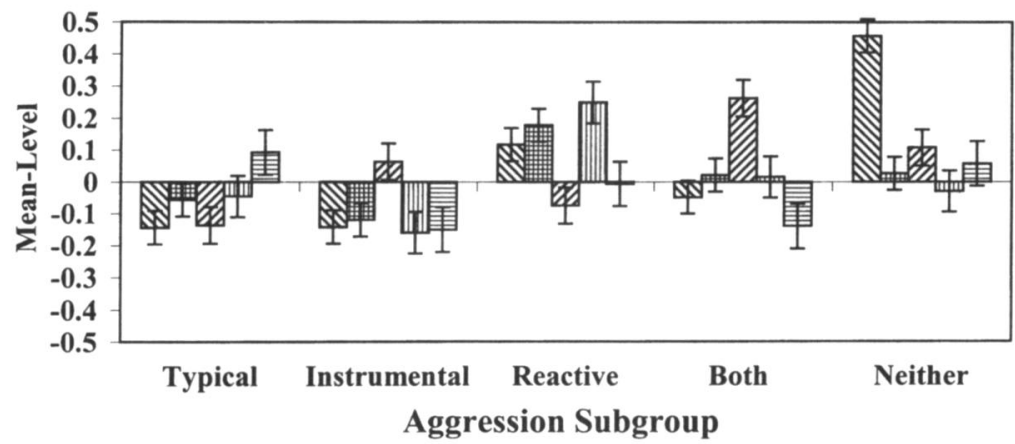

Figure 2. Mean levels of "pure" overt and relational aggression by subtypes of function.

and relational aggression. A few effects for the control variables emerged. Boys were higher than girls on overt aggression as rated by the self, $F(1,1722=6.42), p<.01$, peers, $F(1,1722=34.87), p<.01$, and teachers, $F(1,729=24.96), p<.01$. For best-friend ratings, a gender by grade interaction emerged, $F(2,1163=5.27), p<.01$, reflecting large gender differences (favoring boys) in the later grades but smaller in the younger grades. No gender differences emerged for the ratings of relational aggression, but two grade effects were found, one for best friend ratings, $F(2,1163=4.66), p<.01$, and one for teacher reports $F(2,729=4.06), p<.01$. Teachers reported more relational aggression with age while best friends reported less relational aggression with age. 


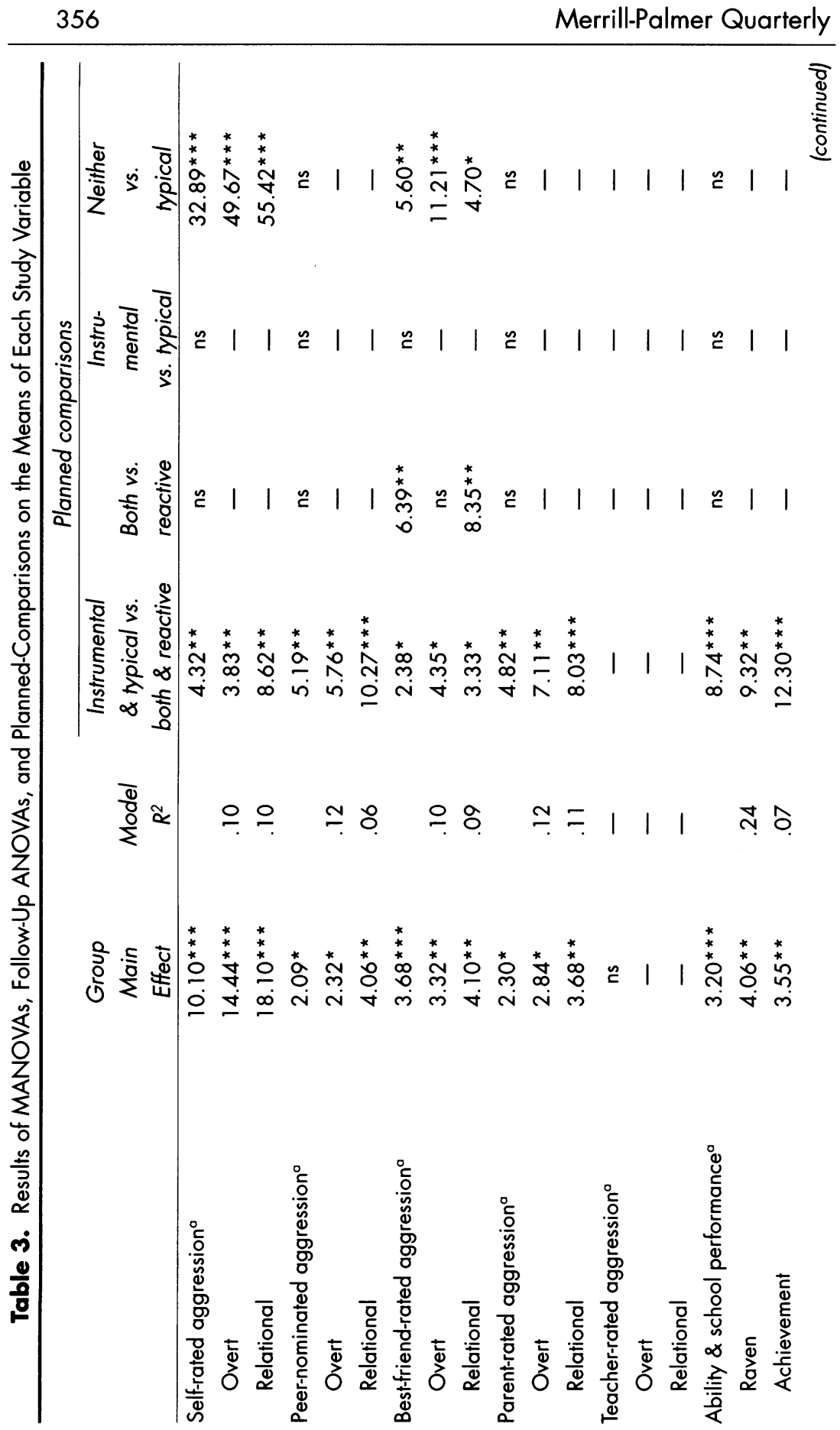




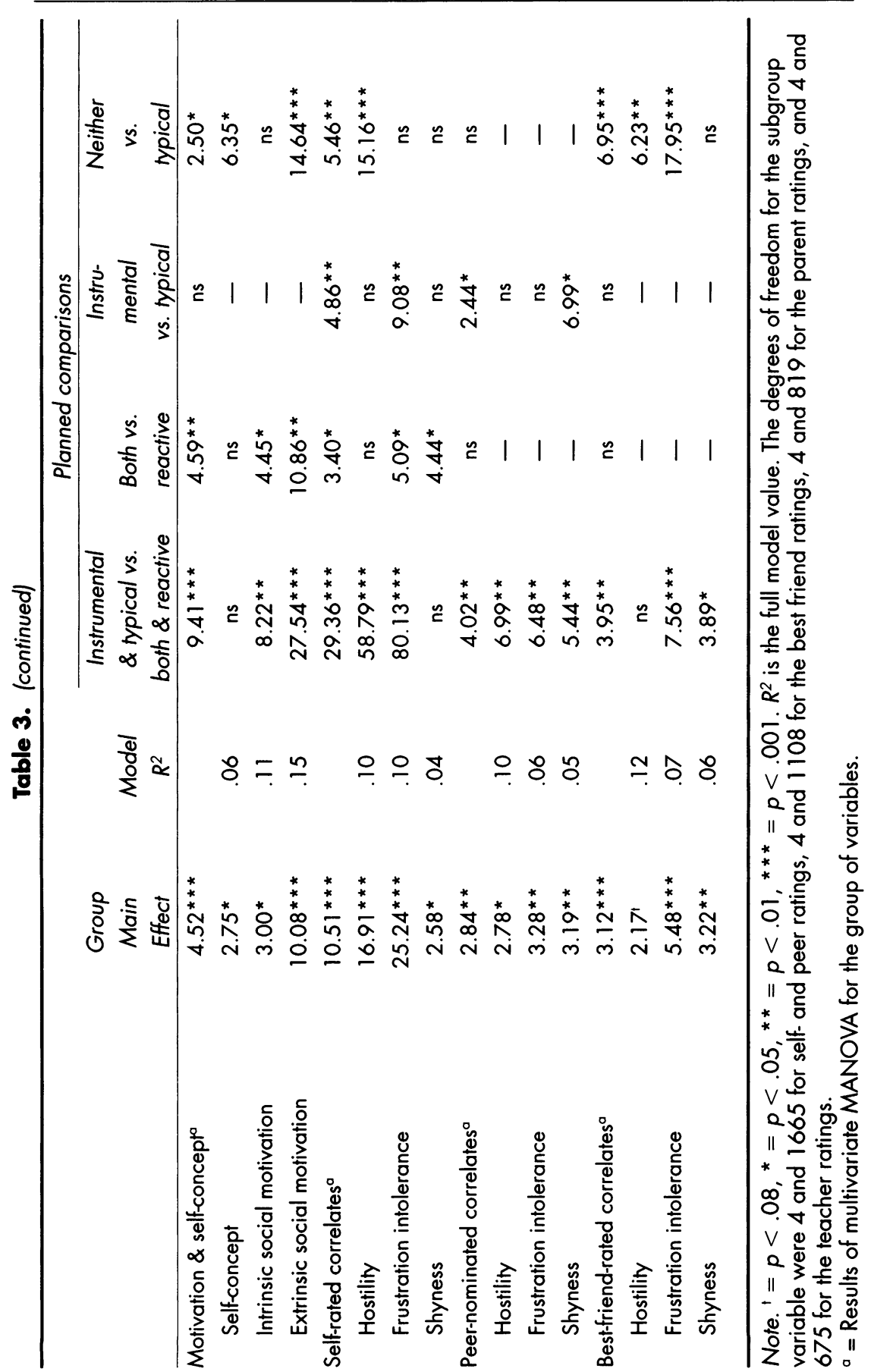


Finally, one ethnicity effect emerged for the parent report, $F(1,876=$ 9.64), $p<.01$, with the minority participants showing higher amounts of overt aggression than the majority participants.

Turning to the subgroup differences on the correlates, the five aggression subgroups differed on each of the selected variables. Although a number of gender, grade, or ethnicity main effects emerged, very few interactions were significant. For Raven, older students performed better than younger students, $F(2,1722=42.25), p<.01$. For achievement, girls outperformed boys, $F(1,1722=9.01), p<.01$. For self-concept, older students reported greater amounts than younger students, $F(2,1722=10.39), p<.01$, and majority students reported greater amounts than the minority students, $F(1,1722=8.28), p<.01$. Girls reported higher levels of intrinsic motivation than did boys, $F(1$, $1722=32.07), p<.01$, and younger students reported higher levels than older students, $F(2,1722=5.41), p<.01$. For the extrinsic motivation differences, boys were higher than girls, $F(1,1722=14.44), p<$ .01 , older students were higher than younger students, $F(2,1722=$ $26.46), p<.01$, and majority students were higher than minority students, $F(1,1722=13.40), p<.01$. The three-way interaction of group by grade by ethnicity, $F(8,1722=3.32), p<.005$, was inconsistent and uninterpretable, suggesting that it emerged as a chance fluctuation. Self-reported hostility was greater in older students than younger students, $F(2,1722=5.36), p<.01$, and it was more pronounced in minority students than in the majority students for the reactive and both subgroups and less pronounced in the typical and instrumental subgroups, $F(4,1722=4.53), p<.01$. Both peer nominated, $F(1,1722$ $=28.74), p<.01$, and best-friend rated, $F(1,1163=34.33), p<.01$, hostility were higher in boys than girls. Finally, peer-nominated shyness was greater in girls than boys, $F(1,1722=6.29), p<.01$.

Regarding our focal analyses of differences among the five aggression subgroups, the adjusted means (i.e., controlling for the covariate effects) for these subgroups are presented in Figures 3 and 4 (for comparison purposes, Appendix A contains the raw means and standard deviations for all variables). Three patterns are of particular note in these figures and supported by the planned comparisons listed in Table 3 . First, the reactive group and the both group showed consistent maladaptive patterns across the outcomes and the both group revealed generally more pronounced negative patterns. Second, the instrumental group was very much like the typical group with each group showing generally adaptive and well-adjusted patterns across the outcomes. Finally, contrary to our expectations, the neither group evinced a number of patterns that are particularly maladaptive (see also Table 3). 


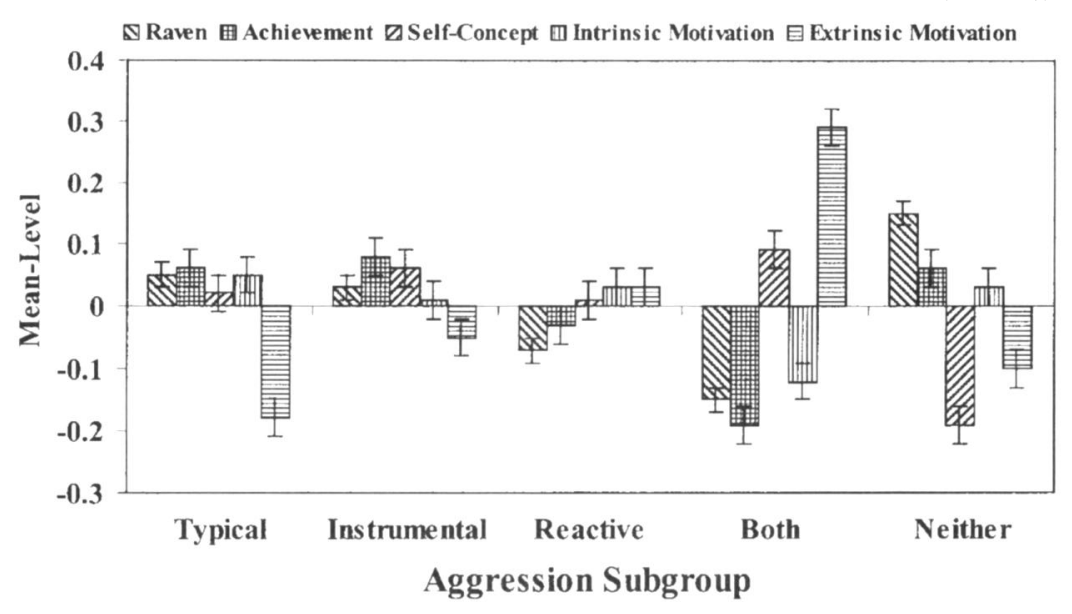

Figure 3. Self-reported mean-level differences on the possible antecedent and consequent correlates.

\section{Discussion}

The unique profiles associated with the different subgroups of aggression illustrate the advantages of utilizing subtypes to examine aggressive behavior. Three of the profiles appear to be maladaptive in nature, but differ in their specifics. Two of the profiles appear to be quite adaptive (i.e., the typical and instrumental groups), suggesting that, at least in this age range, some aggression may be normative and beneficial to social developmental adjustment. The most obvious implication of the subgroup differences is for assessment and intervention programs, which would need to adopt different foci depending on where an individual falls within this taxonomy. Before discussing the profiles of the subtypes, we turn first to the issue of differences among reporters' views.

\section{Differences Among Reporters' Views}

The cross-rater correlations for overt and relational aggression showed little agreement (see Table 2). This inconsistency emphasizes the importance of interpreting results cautiously depending on the reporter used. These discrepancies are likely related to the different contexts in which the different reporters interact with the participants and the attendant bias of a given reporter (Achenbach et al., 1987). Peer and teacher reports were moderately correlated given that they 
A) Self-Report

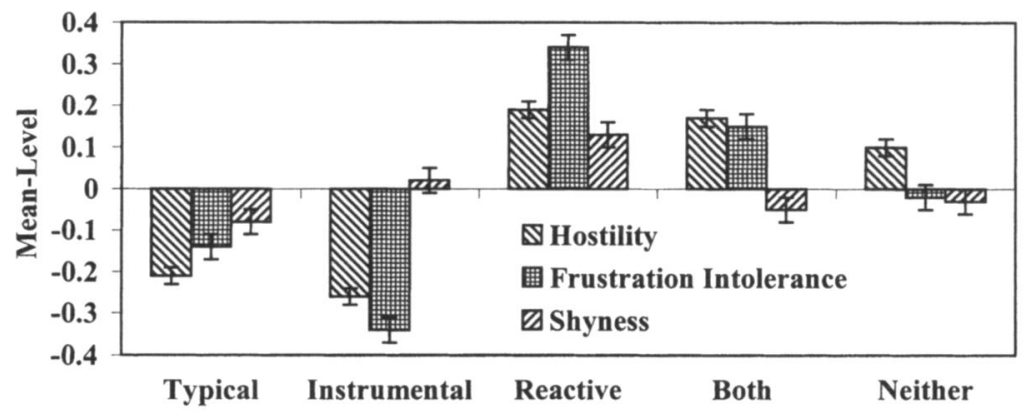

B) Peer Report

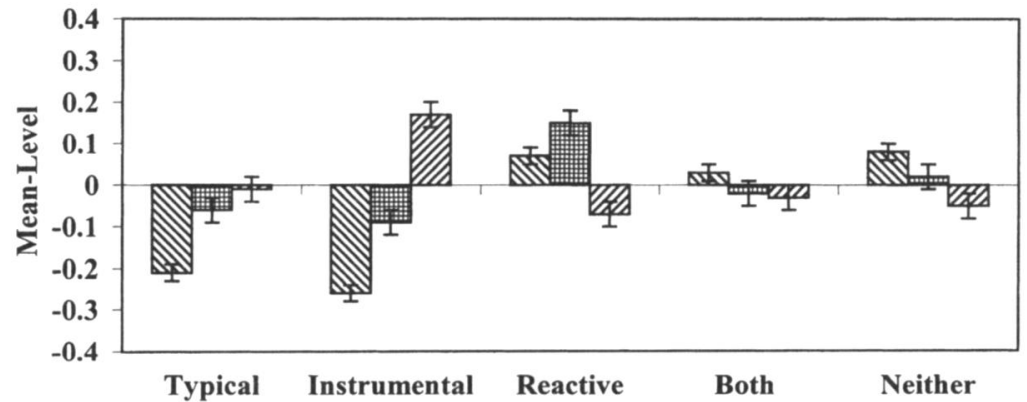

C) Friend Report

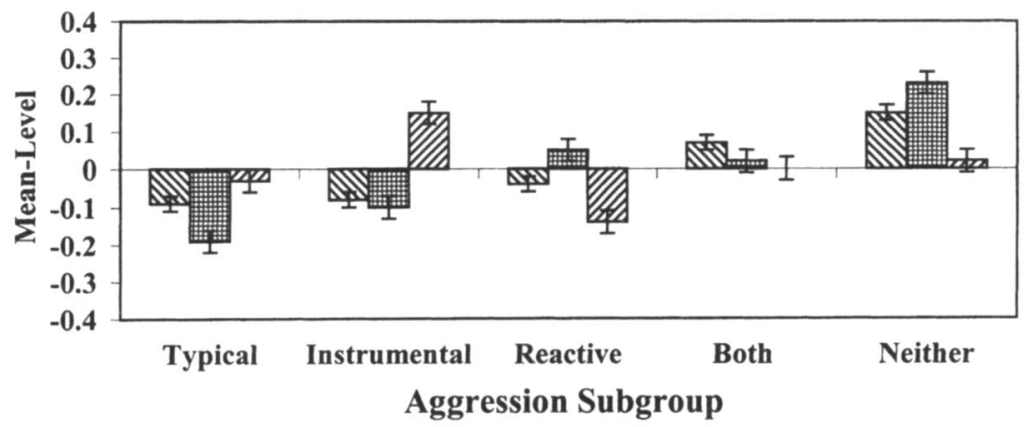

Figure 4. Mean levels on hostility, frustration intolerance, and shyness across three raters. 
share a similar vantage point on the school setting. The least consistency was between friend and parent reports, suggesting that adolescents behave differently when with their parents than with their friends. There was a slight tendency for the cross-reporter correlations of overt aggression to be higher than those of relational aggression (particularly for the peer-teacher cell), which makes intuitive sense given that overt aggression tends to be highly visible while relational aggression is a more subtle behavior that might not be apparent to all observers.

The self-, friend-, and parent-reports of aggression (see Figure 2) were generally similar in their relative patterns across the five groups, with a few notable exceptions (outlined later). This similarity is likely related to the fact that friends and parents have many interactions with the adolescent across numerous contexts, and thus know him or her better than peers and teachers. Regarding the reports of hostility, frustration intolerance, and shyness, two general observations can be made. First, the between-group differences were larger for the self-reports than for the peer and friend reports (as was true for the aggression ratings). This difference is likely related to a self-report bias that enhances the pattern of differences, given that the subgroups are also based on self-report. However, the second general observation is that self-, peer-, and friend-reports showed roughly parallel patterns of mean-level differences, with a few notable exceptions.

The general convergence across reporters indicates that the patterns are veridical but the magnitudes of the differences depend on a given reporter's vantage point. On the other hand, the differences among reporters highlight the importance of understanding why and when to use different reporters to report on different aggressive behaviors.

\section{Characterizing the Subgroups}

\section{The Typical Group}

Along with the instrumental group, the typical group was the least aggressive on both the overt and relational forms of aggression. These youth also exhibited generally adaptive and well-adjusted patterns on the correlates: They do well in school, they are reasonably smart, they have a positive self-concept, they are not too shy, they are able to regulate their feelings of frustration, they do not harbor hostile feelings toward others, and they are more intrinsically than extrinsically motivated to acquire and maintain friendships. This typical group reflects the bulk of our sample of youth and for the most part they should be considered our "control" group. The validity check regarding the relations across the correlates for this group generally supports this view. 
THE INSTRUMENTAL GROUP

As mentioned, the instrumental and typical groups were generally similar in their levels of aggression as reported by self, peer, and parent. The patterns diverged for friend and teacher reports. The friends of the instrumentally aggressive youth saw them as more relationally and more overtly aggressive than did the friends of the typical group. Perhaps the more intimate perspective of the best friend may be privy to the few episodes of aggression that result in beneficial outcomes. Friends may also be accomplices to acts of relational aggression against a particular target. The teachers of the instrumentally aggressive youth rated them as quite low on relational aggression and, surprisingly, the teachers rated typical children as above average (the pattern was similar but nonsignificant for overt aggression). If the instrumental youth are more planful and goal oriented about using aggression, they likely would exhibit their aggressive acts more carefully, out of view of the teacher. The general pattern suggests that adolescents who utilize aggression in instrumental ways appear to be no more aggressive than typical children; however, when they use aggression, they appear to do so in measured ways and in contexts where friends see it, but teachers do not.

Like typical children, instrumental youth do well in school and have a positive self-concept. Their levels of intrinsic and extrinsic motivations were both about equal and at the average for the sample. Also like the typical group, the instrumental youth do not harbor hostile feelings toward others and they are able to regulate feelings of frustration, even more so than the typical children. The story for shyness was somewhat different. The peers (and to some extent friends; see Figure 4) of the instrumental youth see them as quite shy, but the youth themselves report that they are no more shy than average. Children who aggress to get what they want would need to feel capable of exerting themselves when desired (i.e., not feel shy); these episodes may be sufficiently rare that peers do not perceive such a connection. A clear overall pattern for this subgroup that emerges is that they do not appear to have any associated social or academic deficits, even though they willfully and planfully employ aggression to meet their goals.

\section{The Reactive Group}

The levels of aggression for the reactive group were generally above average, but the notable finding was that the parents of reactively aggressive youth reported considerable levels of overt and relational aggression. If parents are witness to these levels of aggression, it suggests that the home and family related contexts may be the settings 
in which these children are most aggressive. Perhaps siblings or the children of the parents' friends are the recipients of the aggressive behavior. It might also be that the parent-child relationship is conflictual characterized by both overt (e.g., physical tantrums) and relational (e.g., playing one parent against the other) forms of aggression.

Except for the slightly lowered levels of intellective skill, the reactive group was pretty much at the average on achievement, self-concept, and motivation. As expected the reactive youth showed considerable frustration intolerance and elevated levels of hostility. Because the reactive group mostly responds to perceived provocation with aggressive behavior, their lack of ability to control their frustration is not surprising. These episodes of reactive aggression may contribute to the levels of hostility. Interestingly, a differential pattern emerged for shyness, which was pretty much opposite that of the instrumental group. Reactive youth self-report that they are shy, but their friends and their peers see them as generally outgoing (or at least near average in the case of the peer reports). Although reactive youth may see themselves as shy, their aggressive acts, which are generally visible because they are provoked, may be seen as a reflection of an outgoing person by peers and friends (i.e., an attributional bias, perhaps).

\section{THE Both Group}

Those adolescents who use aggression in both ways (reactively and instrumentally) engage in aggressive behavior most often, alongside the neither group. We expected that the both group would evince high levels of aggression because of the greater number of contexts and circumstances in which they potentially could aggress. In terms of the motivational correlates, their motivational imbalance is striking. They reported the lowest levels of intrinsic motivation to establish and maintain friendships (i.e., for their inherent joy and satisfaction) and, at the same time, they reported the highest levels of extrinsic motivation (i.e., to be popular, gain approval, etc.). The motivation literature has long been clear on the undermining effects of extrinsic motivation (see e.g., Deci \& Ryan, 1985), and coupled with the low levels of intrinsic motivation, puts this group at risk for generally dissatisfying relationships that may lead to other long term adjustment problems and feelings of alienation from the peer world. Although this group does not appear to suffer from a lowered self-concept, their friends' views might suggest otherwise. The reciprocal best friends of these children see them as highly relationally aggressive, moderately overtly aggressive, and hostile. In terms of their academic profiles, this group was the lowest performing and scored lowest on the measure of intellective skill. One 
might speculate that this group would be at risk for school drop out because of their low academic standing and the potential for later adjustment problems in their social worlds.

\section{THE NeITHER GROUP}

The high levels of aggression for the neither group was absolutely opposite of our expectations. They scored highest on intellective skill, but perform only slightly above average in school-a generally underachieving pattern. Although their motivations for social relationships were in the adaptive direction, their social self-concept was strikingly lower than any of the other subtypes. These youth report that they have hostile feelings toward others and their friends agree, as does the peer world. The friends of these youth also report that they are generally frustration intolerant. This group does not appear to be particularly shy.

In our view, the profile of these youth depicts a hostile aggressive pattern, wherein aggression is neither provoked nor wielded for gain. Perhaps the aggressive episodes are an attempt to enhance a low selfconcept. Moreover, the underachieving nature of this group suggests that the poor adaptations in the social world may be undermining their ability to perform well in school. Clearly future work will need to identify the manner in which their academic world is hampered by their social world. Clues to this relationship could then be used to tailor an intervention program specifically for this category of aggressive youth.

\section{Limitations and Questions for Future Research}

Some of the deficiencies of this study warrant discussion. First, the reliance on self-report of the functional purpose of aggressive acts is not without potential bias. The degree to which other factors such as self-presentation bias, acquiescent-response bias, and the like are involved does weaken the virility of our classifications. Clearly, further criterion-related validity work would help to establish the accuracy of the taxonomic classifications. In addition, other methodologies such as the use of vignettes, structured interviews, or controlled experimental procedures (e.g., Hawley \& Little, 1999) could be used that reduce the potential impact of self-report biases.

A second limitation that future work will need to address is the lack of absolute cutoffs for classifying youth. We chose to use the relative differential in the scores from this representative sample of German youth to establish the groups for this study. However, in order for practitioners to be able to use these categories meaningfully, diagnostic 
tools will need to be developed that include normed criteria for classification.

Third, our study only intimated potential antecedents and consequents of the different subgroups of aggressive youth. This strictly cross-sectional approach does beg a number of questions that only longitudinal work could address. For example, are characteristics such as shyness, frustration intolerance, and hostility antecedents to aggressive behavior or are they consequents of it? Are the subgroups of aggressive youth stable over time or are they dependent upon age and context? In this longitudinal work, expanding the breadth of correlates would also serve to help elucidate the nature and meaning of these profiles.

Lastly, one question for future work that would provide a critical piece for this puzzle is a detailed examination of who the recipients of the different aggressive acts are. We would postulate, for example, that instrumentally aggressive youth would not choose "easy targets" like the neither group might, but instead would choose targets that hold a desired resource or who are at about the same level of social dominance. A well-placed and successful aggressive act toward a near challenger would have a double effect of thwarting the challenger and sending a message to all other challengers at or below the thwarted challenger's rank: "Don't even think about it." Similarly, the source of the elevated reports by parents would be better understood knowing who the recipients were.

\section{Conclusions}

Overall, our efforts to classify aggressive children into subgroups successfully revealed striking profiles associated with the subgroups with direct implications for intervention work. These unique configurations suggest that an intervention designed for one type of aggressive behavior (e.g., reactive aggression or bullying) might not be effective for another. For example, an intervention trying to curb hostility will be more effective for children who display reactive aggression and less effective for children who exhibit instrumental aggression. Many intervention programs for aggressive children target frustration intolerance, hostile attribution bias, and impulsive responding to provocative stimuli (Kazdin, 1995). Our findings suggest that although these dimensions may be important points of intervention for some children (i.e., the reactive and both subtypes), they are likely to be less important in the treatment of other aggressive children (i.e., the instrumental and neither subtypes). For the neither group, other motivations need to be considered such as problems with self-esteem. In other words, more 
attention needs to be given to assessing the functions of aggression in order for intervention programs to be optimally effective.

\section{References}

ACHENBACH, T. M., MCCONAUGHY, S. H., \& HOWELL, C. T. (1987). Child/adolescent behavioral and emotional problems: Implications of cross-informant correlations for situational specificity. Psychological Bulletin, 101, 213-232.

ASENDORPF, J. (1989). Soziale Gehemmtheit und ihre Entwicklung. In D. Albert, K. Pawlik, K.-H. Stapf, \& W. Stroebe (Eds). Lehr- und Forschungstexte Psychologie, 29. Berlin: Springer.

ATKINS, M. S., \& STOFF, D. M. (1993). Instrumental and hostile aggression in childhood disruptive behavior disorders. Journal of Abnormal Psychology, 21, 165-178.

COIE, J. D., \& DODGE, K. A. (1998). Aggression and antisocial behavior. In W. Damon (Series Ed.) \& N. Eisenberg (Vol. Ed.), Handbook of child psychology: Vol. 3. Social, emotional, and personality development $\left(5^{\text {th }} \mathrm{ed}\right.$., pp. 779-862). New York: Wiley.

CRICK, N. R., CASAS, J. F., \& MOSHER, M. (1997). Relational and overt aggression in preschool. Developmental Psychology, 33, 579-588.

CRICK, N. R., \& GROTPETER, J. K. (1995). Relational aggression, gender, and social-psychological adjustment. Child Development, 66, 710-722.

DECI, E. L. \& RYAN, R. M. (1985). Intrinsic motivation and self determination in human behavior. New York: Plenum.

DELVEAUX, K. D., \& DANIELS, T. (2000). Children's social cognitions: Physically and relationally aggressive strategies and children's goals in peer conflict situations. Merrill-Palmer Quarterly, 46, 672-692.

DODGE, K. A., \& COIE, J. D. (1987). Social-information-processing factors in reactive and proactive aggression in children's peer groups. Journal of Clinical Child Psychology, 21, 210-217.

HARTER, S. (1982). The perceived competence scale for children. Child Development, 53, 87-97.

HAWLEY, P. H. (1999). The ontogenesis of social dominance: A strategybased evolutionary perspective. Developmental Review, 19, 97-132.

HAWLEY, P. H., \& LITTLE, T. D. (1999). On winning some and losing some: Social dominance in toddlers. Merrill Palmer Quarterly, 43, 185-214.

HAWLEY, P. H., LITTLE, T. D., \& PASUPATHI, M. (2003). Winning friends and influencing peers: Strategies of peer influence in late childhood. International Journal of Behavioral Development, 26, 466-474.

KAZDIN, A. E. (1995). Conduct disorders in childhood and adolescence $\left(2^{\text {nd }}\right.$ ed.). Thousand Oaks, CA: Sage.

KELTNER, D., YOUNG, R. C., \& BUSWELL, B. N. (1997). Appeasement in human emotion, social practice, and personality. Aggressive Behavior, $23,359-374$. 
LEDINGHAM, J. E., YOUNGER, A., SCHWARTZMAN, A. E., \& BERGERON, G. (1982). Agreement among teacher, peer, and self-ratings of children's aggression, withdrawal, and likability. Journal of Abnormal Child Psychology, 10, 363-372.

LITTLE, T. D., JONES, S. M., HENRICH, C. C., \& HAWLEY, P. H. (2003). Disentangling the "whys" from the "whats" of aggressive behavior. International Journal of Behavioral Development, 27, 122-183.

LITTLE, T. D., \& WANNER, B. (1997). The Multi-CAM: A multidimensional instrument to assess children's action-control motives, beliefs, and behaviors (Materialen aus der Bildungsforschung, No. 59). Berlin: Max Planck Institute for Human Development.

MAGNUSSON, D. (1998). The logic and implications of a person-oriented approach. In R. B. Cairns, L. R. Bergman \& J. Kagan (Eds.), Methods and models for studying the individual (pp. 33-64). Thousand Oaks, CA: Sage.

OLWEUS, D. (1979). Stability of aggressive reaction patterns in males: A review. Psychological Bulletin, 86, 852-875.

PAKASLAHTI, L., \& KELTIKANGAS-JAERVINEN, L. (2000). Comparison of peer, teacher and self-assessments on adolescent direct and indirect aggression. Educational Psychology, 20, 177-190.

POULIN, F., \& BOIVIN, M. (1999). Proactive and reactive aggression and boys' friendship quality in mainstream classrooms. Journal of Emotional \& Behavioral Disorders, 7, 168-177.

POULIN, F., \& BOIVIN, M. (2000). Reactive and proactive aggression: Evidence of a two-factor model. Psychological Assessment, 12, 115-122.

PRICE, J. M., \& DODGE, K. A. (1989). Reactive and proactive aggression in childhood: Relations to peer status and social context dimensions. Journal of Abnormal Psychology, 17, 455-471.

PULKKINEN, L. (1996). Proactive and reactive aggression in early adolescence as precursors to anti- and prosocial behavior in young adults. Aggressive Behavior, 22, 241-257.

RAVEN, J. C. (1971). Standard progressive matrices (SPM). London: Lewis \& Co.

SEITZ, W. \& RAUSCHE, A. (1992). Persoenlichkeitsfragebogen fuer Kinder zwischen 9 und 14 Jahren [Personality inventory for children between 9 and 14 years]. Goettingen: Hogrefe.

TREMBLAY, R. E. (2000). The development of aggressive behavior during childhood: What have we learned in the past century? International Journal of Behavioral Development, 24, 129-141. 


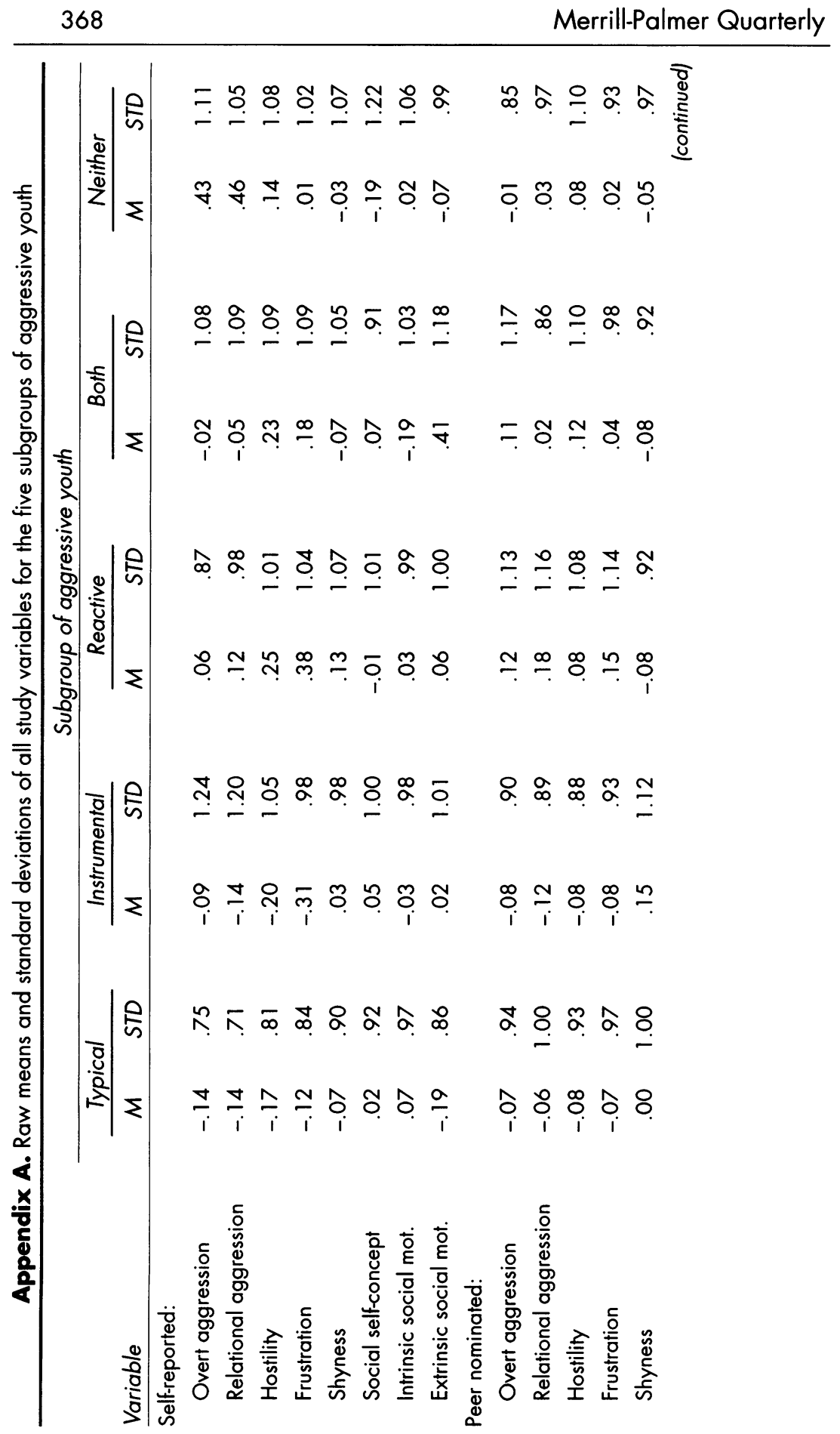




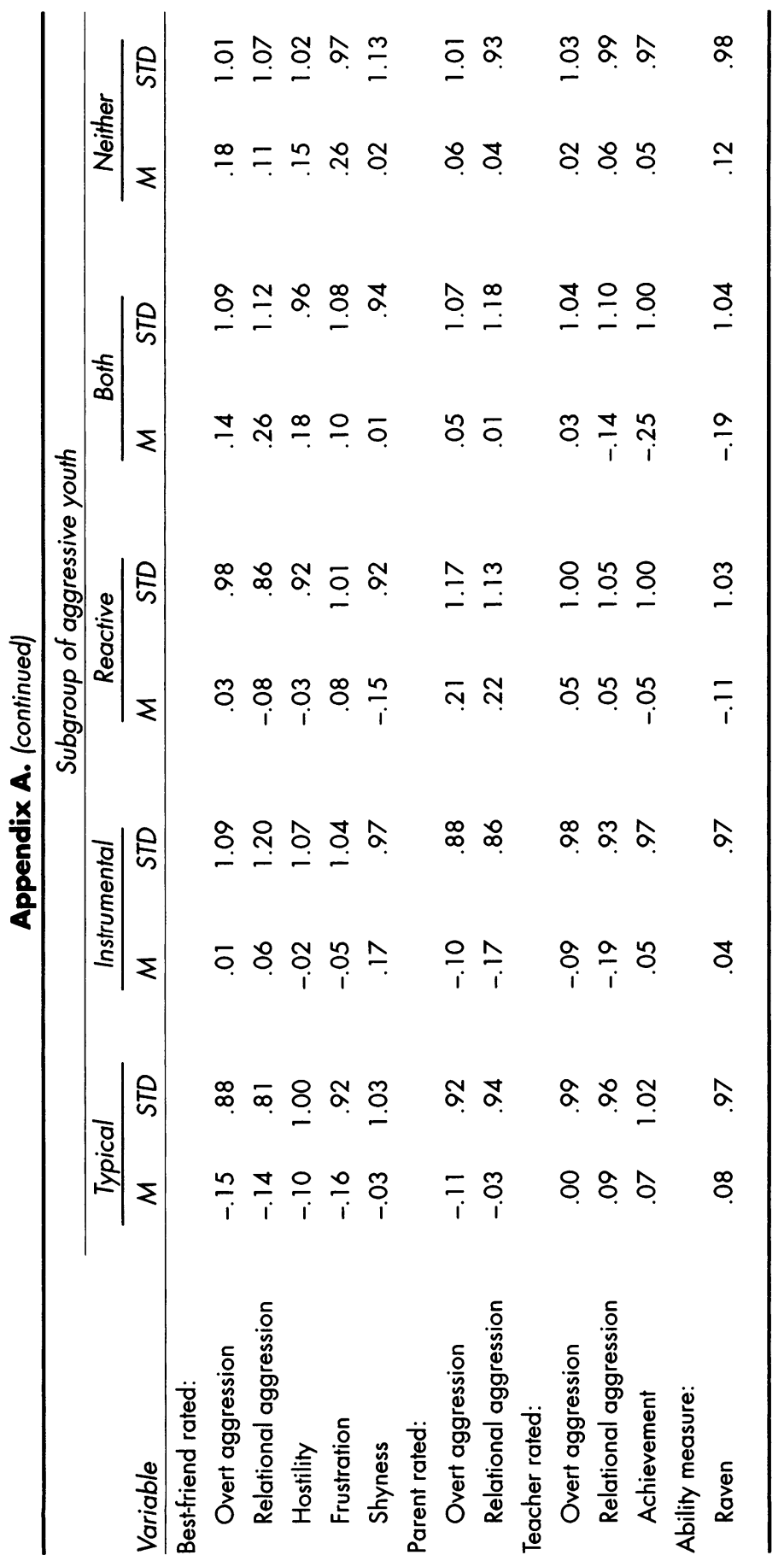

